\title{
Kinetic variations in Acid-Catalyzed Monosaccharide Conversion
}

\author{
Meier, Sebastian
}

Published in:

Catalysis Communications

Link to article, DOI:

10.1016/j.catcom.2019.105894

Publication date:

2020

Document Version

Peer reviewed version

Link back to DTU Orbit

\section{Citation (APA):}

Meier, S. (2020). Kinetic variations in Acid-Catalyzed Monosaccharide Conversion. Catalysis Communications, 135, [105894]. https://doi.org/10.1016/j.catcom.2019.105894

\section{General rights}

Copyright and moral rights for the publications made accessible in the public portal are retained by the authors and/or other copyright owners and it is a condition of accessing publications that users recognise and abide by the legal requirements associated with these rights.

- Users may download and print one copy of any publication from the public portal for the purpose of private study or research.

- You may not further distribute the material or use it for any profit-making activity or commercial gain

- You may freely distribute the URL identifying the publication in the public portal

If you believe that this document breaches copyright please contact us providing details, and we will remove access to the work immediately and investigate your claim 
Kinetic variations in Acid-Catalyzed Monosaccharide Conversion

\author{
Sebastian Meier*
}

*Department of Chemistry, Technical University of Denmark, Kemitorvet, Bygning 207, 2800 Kgs. Lyngby,

Denmark, E-mail: semei@kemi.dtu.dk 
Abstract:

Kinetic models for the conversion of abundant carbohydrates have often remained controversial. Direct spectroscopic observations show that conversion of ketoses by Lewis acidic salts follows an exponential time course, while the corresponding conversion of aldoses follows a second order kinetics in various solvents and using various metal chloride catalysts. Brønsted acid catalyzed conversion of glucose and fructose displays two kinetic regimes due to the competition between the kinetically favoured formation of anhydrosugars and the thermodynamically favored formation of furanics. Thus, slow kinetic phases occur towards the end of glucose conversion by Lewis and Brønsted acidic catalysis, albeit for different reasons.

Keywords: Brønsted acid, Glucose, in situ NMR, Kinetics, Lewis acid, Reaction order

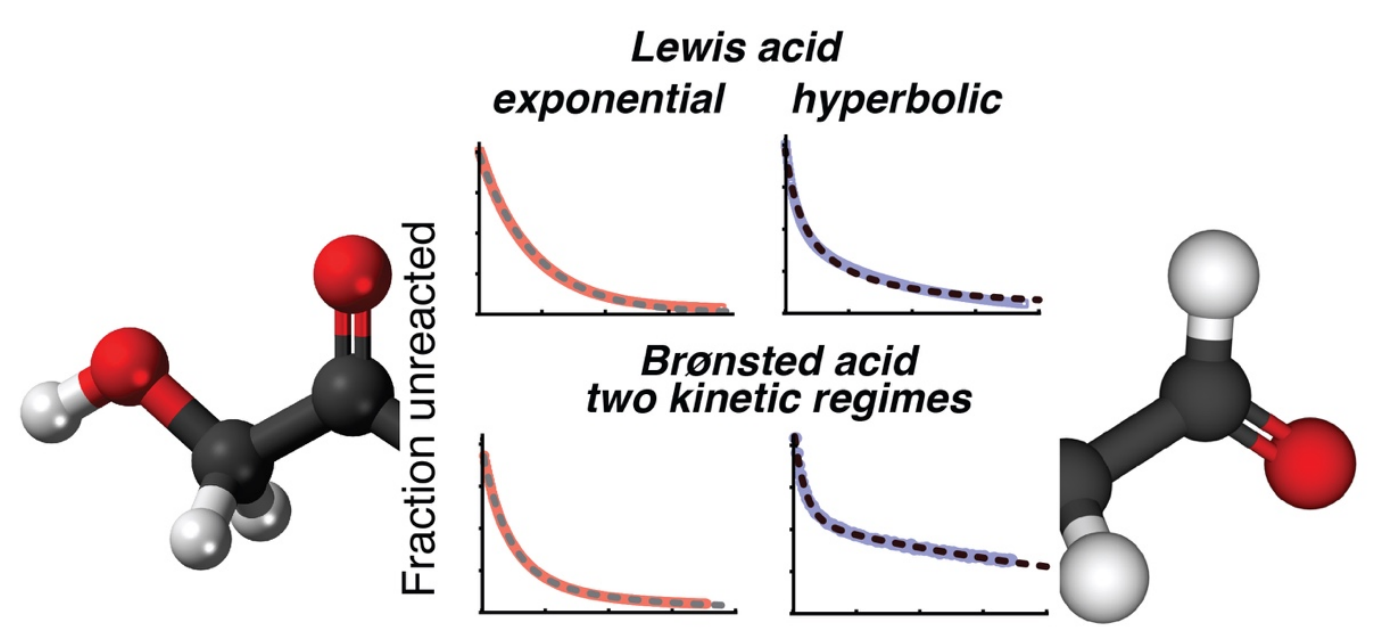




\section{Introduction}

Sustainable production of chemicals and energy has been a top priority in recent chemocatalytic research. Dehydration of sugars in acidic media is arguably among the most important pathways that have been explored in order to generate precursors with reduced oxygen content [1-5]. For the conversion of hexoses, these pathways lead to hydroxymethylfurfural (HMF), which is widely investigated as a prospective chemical precursor for fuels and materials [6-9]. The urgency of discovering alternatives to petrochemical processes has led to a strong focus on the discovery of catalyst systems for the formation of known products at high yields. In contrast, experimental mechanistic and kinetic studies have remained sparser [4, 10-15]. As a consequence, comparably high-yielding byproducts in chemocatalytic carbohydrate conversion have been discovered only recently $[16,17]$, active site structures have remained difficult to fully comprehend $[18,19]$, kinetic models and reaction order have remained controversial [5, 20-22], as has the usage of competing acyclic and cyclic pathways to HMF [23-25].

Conflicting previous interpretations of kinetic profiles in carbohydrate valorization indicate the necessity for direct and quantitative high-resolution methods to characterize reaction kinetics. Acid catalyzed carbohydrate conversion reactions are often characterized by rate-limiting initial steps and a concomitant dearth of accumulating intermediates. In such instances, time-resolved in situ spectroscopy can stipulate reaction progress kinetic analysis to obtain insight into elusive details of the catalytic cycle. Different kinetic regimes, reaction mechanisms and stoichiometry may thus be inferable from substrate conversion kinetics (Scheme 1).

High-resolution NMR spectroscopy was employed herein to track carbohydrate reaction conversions due to the suitable prowess of NMR in providing quantitative signals that are baselineseparated from isomeric species and from dehydration or cleavage products. In situ NMR was used in the kinetic study of carbohydrate conversion to provide kinetics of a rarely studied elementary step

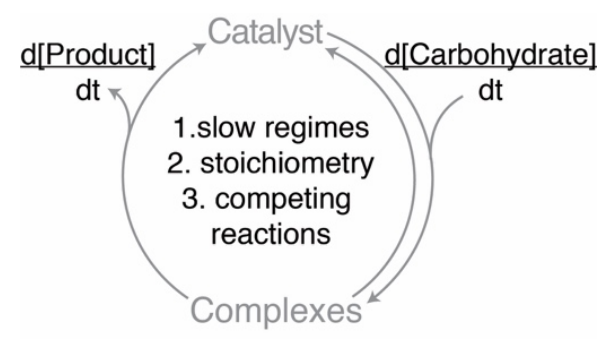

Scheme 1. Topics addressed using in situ NMR kinetic analysis of carbohydrate conversion. 
(initial conversion) in a multistep pathway. Kinetic comparisons between different substrates under identical reaction conditions were obtained in this way. Various solvent systems, Lewis acidic salts and Brønsted acid catalysis were probed. Reaction progress was consistent with a mixed reaction order for various Lewis acidic salts, and with a bi-exponential trend in Brønsted acidic hexose conversion to HMF. Both the Lewis acid and the Brønsted acid catalyzed reactions of glucose thus showed inherently slow conversion at high substrate conversion.

\section{Experimental}

\section{Chemicals}

All chemicals were purchased from Sigma Aldrich (St. Louis, MO, USA) or Carbosynth (Compton, UK). Catalyst salts were weighed into a $1.5 \mathrm{ml}$ Eppendorf safelock tube at concentrations of 2.5-10 mol\% relative to hexoses or pentoses and pre-dissolved in the solvent of choice. The pre-dissolved catalyst solution was added to the substrate weighed into a $1.5 \mathrm{ml}$ Eppendorf safelock tube and reaction solutions were mixed immediately prior to transfer to a $5 \mathrm{~mm} \mathrm{NMR} \mathrm{sample} \mathrm{tube,} \mathrm{which} \mathrm{was} \mathrm{rapidly}$ transferred to an NMR spectrometer equilibrated to the desired temperature for in situ kinetic experiments. Substrate concentrations on the order $0.5 \mathrm{M}$ were used for unlabeled substrates and $0.25 \mathrm{M}$ were used for ${ }^{13} \mathrm{C}$ enriched substrates.

\section{In situ NMR spectroscopy}

All in situ NMR spectra were acquired on a Bruker (Fällanden, Switzerland) Avance III $600 \mathrm{MHz}$ (14.1 T) magnet equipped with a BBO smart probe and shim gas cooling. The in situ spectra of inidividual carbohydrate substrates and of aldoses and ketoses of same length were acquired as pseudo-2D spectra. Series of ${ }^{1} \mathrm{H}$ spectra were acquired by sampling the FID for 1.8 seconds with an inter-scan recycle delay of 2 seconds, employing composite pulses and presaturation. Series of ${ }^{13} \mathrm{C}$ spectra were acquired by sampling $64 \mathrm{k}$ complex data points in the FID for 1.8 seconds with an inter-scan recycle delay of 4.2 seconds using inverse-gated decoupling. Integrals of solvent signals indicated a relative error on the order of $1 \%$ for integrations between different time points (Fig. S1). The comparison of aldohexose conversion curves was conducted using a time series of ${ }^{1} \mathrm{H}-{ }^{13} \mathrm{C}$ HSQC spectra sampling 1024 and 256 complex data points in in the ${ }^{13} \mathrm{H}$ and ${ }^{13} \mathrm{C}$ dimension, respectively, with spectral widths of $13.3\left({ }^{1} \mathrm{H}\right)$ and $15\left({ }^{13} \mathrm{C}\right) \mathrm{ppm}$, sampling the NMR signal for $127\left({ }^{1} \mathrm{H}\right)$ and $113\left({ }^{13} \mathrm{C}\right)$ milliseconds. All spectra were processed with extensive zero filling in all dimensions and with baseline correction in Bruker Topspin 3.5pl7 and were subsequently integrated in the same software, where pseudo-2D 
spectra were integrated using the Dynamics center. Experimental details are provided in the Supporting information. Identical kinetic behavior for different tautomers indicated that the tautomers equilibrate rapidly in a pre-equilibrium that is faster than the subsequent isomerization and dehydration reactions at the relevant temperatures (see for instance Fig. S4B). Substrate signals with the least overlap with emerging intermediates or products were thus integrated to represent the time course of substrate conversion.

\section{Data analysis}

Time-resolved measurements were fitted to rate laws for first order, second order, mixed order and bi-exponential first order reactions. The data fitting minimised mean square deviations (chi-squared) between data and fitfunctions in proFit 7 (Quansoft, Switzerland). The reaction rates $v$ of substrate conversion were treated as $v=k[S], v=k[S]^{2}$ and $v=k_{1}[S]+k_{2}[S]^{2}$ for first, second and mixed reaction order rate laws, respectively, where $[S]$ is the substrate concentration and $k$ are the corresponding rate constants. Reactions in Brønsted acidic medium were fitted to a bi-exponential first order rate law as the suitable approximation for reactions rapidly forming kinetic side products in parallel to slower formation of the thermodynamic product [26].

\section{Results and discussion}

\subsection{Aldoses and ketoses behave kinetically differently beyond different rates}

The emphasis of the current study lay on reaction progress kinetic analysis by time-resolved in situ NMR spectroscopy in polar aprotic solvents. These solvents have commonly been described as attractive reaction media for carbohydrate conversion due to low humin formation and the suppression of HMF rehydration and conversion to levulinic acid [24]. Polar aprotic media also often have a high ability to solubilize carbohydrates and favor acid catalysis towards high product yields.

In the presence of $\mathrm{CrCl}_{3}$, glucose is converted to $\mathrm{HMF}$ via fructose as an intermediate and the comparison of glucose and fructose conversion to HMF thus requires special measures. Such a comparison was motivated by the fact that some disagreement has persisted as to whether glucose conversion by Lewis acidic catalysts resembles a first-order or a second-order reaction kinetics [20, 22].

Substrate conversion was probed for a 1:1 mixture of $\left[1-{ }^{13} \mathrm{C}\right]$ glucose and $\left[2-{ }^{13} \mathrm{C}\right]$ fructose. This mixture takes advantage of the ability of NMR to track the provenance of molecular species through isotope labelling under identical reaction conditions: $\left[1-{ }^{13} \mathrm{C}\right]$ glucose and $\left[2-{ }^{13} \mathrm{C}\right]$ fructose were 
predominantly converted to the respective $\left[1-{ }^{13} \mathrm{C}\right]$ and $\left[2-{ }^{13} \mathrm{C}\right] \mathrm{HMF}$ products and these reactions to the same chemical could be distinguished by producing isotopic isomers with the ${ }^{13} \mathrm{C}$ isotope in different positions. Besides functioning as a catalyst, the chromium salt also acted as a relaxation agent, which rapidly restored nuclear magnetization to its equilibrium and thus permitted the rapid accumulation of high-quality NMR spectra [27].

Resultant time courses for the conversion of glucose and fructose and for the formation of $\left[1-{ }^{13} \mathrm{C}\right]$ HMF (from glucose) and of $\left[2-{ }^{13} \mathrm{C}\right] \mathrm{HMF}$ (from fructose) are shown in Fig. 1. Fructose was converted to HMF with initial rates more than an order of magnitude above corresponding initial rates for glucose conversion under identical conditions. In addition, the curves for conversion of glucose and fructose to HMF exhibited different functional forms (Fig. 1). The reaction progress curves for glucose conversion to HMF followed a hyperbolic function, consistent with reaction that is of second order in the substrate concentration, while reaction progress curves for fructose conversion to HMF follow an exponential trend consistent with a first order reaction. As a consequence, HMF yields from glucose continue to increase slowly, similar to curves of HMF increase shown in the literature for ex situ experiments [5]. This slow increase in HMF deriving from glucose may partly contribute to some of the lower yields described for glucose conversion as compared to yields for fructose conversion for acceptable experiment durations. In situ NMR spectra for the parallel formation of furanics from xylose and glucose validated that product formation from neither aldose followed an exponential increase (Fig. S2).
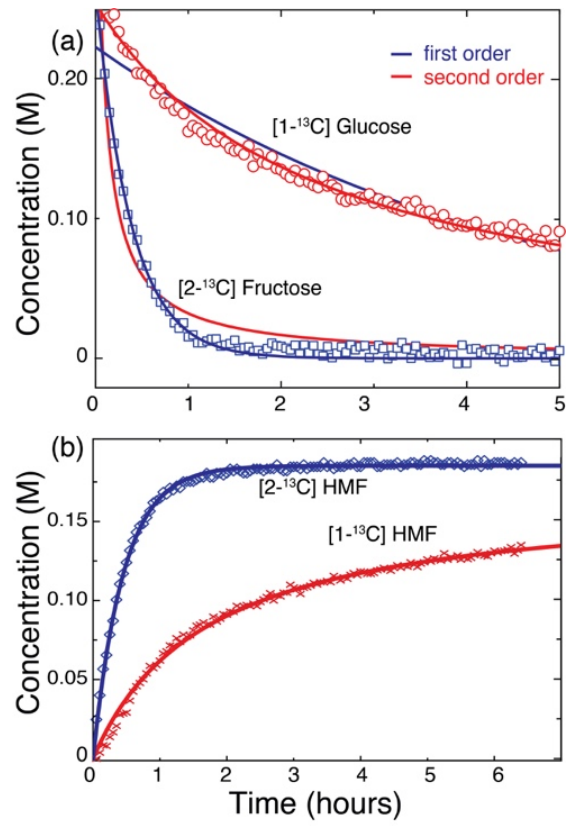
Fig. 1 Reaction kinetics in the $\mathrm{Cr}(\mathrm{III})$-catalyzed conversion of (a) glucose and fructose to (b) HMF in DMSO as tracked by integration of in situ ${ }^{13} \mathrm{C}$ NMR data. Reaction conditions: $25 \mathrm{mg}\left[1-{ }^{13} \mathrm{C}\right]$ glucose, $25 \mathrm{mg}\left[2-{ }^{13} \mathrm{C}\right]$ fructose, $\mathrm{CrCl}_{3} \cdot 6 \mathrm{H}_{2} \mathrm{O}(2.5 \mathrm{~mol} \%$ relative to the hexoses $), 0.6 \mathrm{ml} \mathrm{DMSO}-\mathrm{d}_{6}, 130{ }^{\circ} \mathrm{C}$.

For Brønsted acid catalyzed dehydration of xylose in aqueous solutions, second-order kinetics have been ascribed to the reaction between xylose and furfural $[28,29]$. In the conversion of aldoses by Lewis acidic metal salts in solvents that suppress humin formation, second order kinetics have been ascribed to the formation of 2:1 complexes between the aldose and the metal salt $[5,20]$, while other studies maintained a first-order treatment of aldose conversion in metal salt catalyzed reactions [21, 22]. Kinetic in situ NMR experiments conducted herein showed that xylose conversion was hardly affected by addition of stoichiometric amounts of furfural or glucose to the reaction mixture (Fig. S3). Intermolecular aggregation with reactive intermediates thus does not appear to be the main reason for the second-order substrate kinetics. Second order kinetics may thus reflect recent observations of glucose predominantly in 2:1 complexes with Lewis acidic salts [30]. The kinetic trend of furanics formation itself (Fig. 1b) also indicated that second order kinetics arises in the metal-catalyzed reaction step converting substrate to furanics. Byproducts in these reactions include levulinic acid, disaccharides, isomeric sugars and anhydrosugars [27, 31].

\subsection{Full conversion is slow with different Lewis acidic catalysts, substrates and solvents}

In order to test whether similar functional forms in reaction progress kinetic behavior is observed for different catalysts, $\operatorname{Cr}(I I I)$ was replaced with various other Lewis acidic salts to probe the reaction kinetics in glucose conversion. Among the salts described to show high activity in glucose conversion

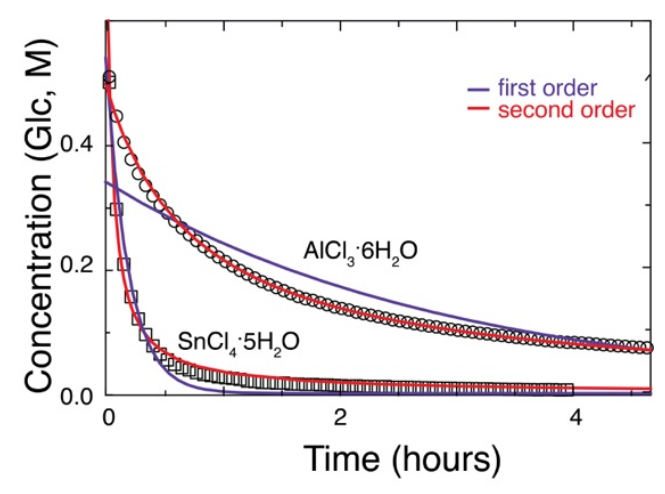


Fig. $2 \mathrm{Al}(\mathrm{III})$ and Sn(IV)-catalyzed conversion of glucose in DMSO as followed by integration of a time series of in situ ${ }^{13} \mathrm{C}$ NMR spectra and fitted to first order and second order models. Reaction conditions: $50 \mathrm{mg}$ glucose, $6 \mathrm{mg} \mathrm{AlCl} 3 \cdot 6 \mathrm{H}_{2} \mathrm{O}$ or $\mathrm{SnCl}_{4} \cdot 5 \mathrm{H}_{2} \mathrm{O}, 130{ }^{\circ} \mathrm{C}$ and $0.55 \mathrm{ml} \mathrm{DMSO}-\mathrm{d}_{6}$.

in DMSO were $\mathrm{Al}(\mathrm{III}), \mathrm{Sn}$ (IV) and In(III) salts [20, 32-34]. When using these catalysts, both the conversion of glucose and the formation of HMF were found to follow second order reaction kinetics (Fig. 2 and Fig. S4, S5).

A comparative study of substrates was then pursued to probe the Lewis acid catalyzed conversion of all eight aldohexoses by $\mathrm{SnCl}_{4}$. Sn(IV) was chosen as a particularly active metal salt in the conversion of glucose (Fig. 2) [34]. As the eight substrates are regioisomers, reaction progress was difficult to track as a series of one-dimensional spectra due to the resultant signal overlap especially in ${ }^{1} \mathrm{H}$ NMR spectra. In contrast, suitably optimized ${ }^{1} \mathrm{H}^{13} \mathrm{C}$ HSQC spectra have adequate prowess in distinguishing carbohydrates in mixtures. Hence, a time series of ${ }^{1} \mathrm{H}^{13} \mathrm{C} \mathrm{HSQC}$ spectra was acquired to track the conversion of all eight linear aldohexoses.

Reaction progress curve analysis validated that conversion of all linear aldohexoses followed hyperbolic kinetics (Fig. 3, Fig. S6). The mean square deviations (chi-squared values) between observed and predicted values showed that each single of the substrate curves was better described by a second order kinetics than by a first order kinetics. Fits to hyperbolic trends in a second order kinetic model were on average approximately five times better than fits to a first order model (Fig. S7). The analysis also showed that deviation of experimental data from first order kinetic trends in Fig. 3 occured at different time points for different substrates, indicating that catalyst deactivation does not cause the slowdown of the reactions at low fractions of unreacted substrate.

Various solvents other than DMSO have attracted interest in the conversion of carbohydrates to furanics due to preferable product yields, purification, or for being biomass-derived solvents. Glucose conversion in propylene carbonate (Fig. S8, S9), $\gamma$-valerolactone (Fig. S10) and [EMIM]Cl (Fig. S11, S12) showed agreement between reaction progress and a second order model. Conversion proceeded noticeably faster than predicted for low substrate concentration, possibly through contribution from first order kinetics, as could be expected in the presence of predominant 2:1 and minor 1:1 substrate:metal complexation [30]. Overall, real-time NMR spectroscopic observations detected that aldose conversion follows second order kinetics for a broad range of solvents, substrates, and Lewis acidic salts. 


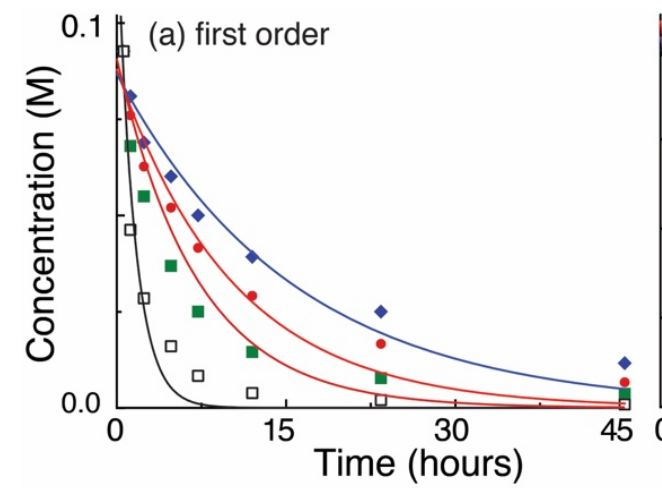

(b) second order

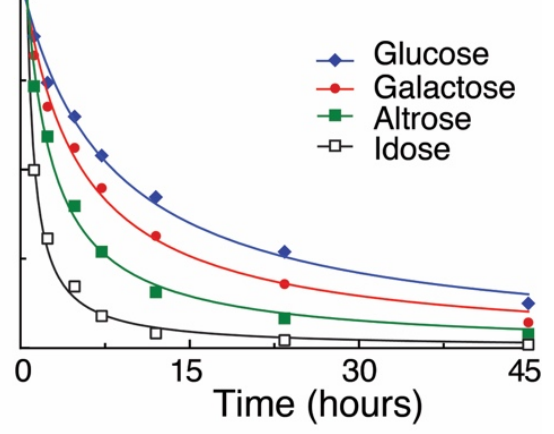

Fig. $3 \mathrm{Sn}(\mathrm{IV})$-catalyzed conversion of four selected aldohexoses in DMSO, as followed with in situ ${ }^{1} \mathrm{H}$ ${ }^{13} \mathrm{C}$ HSQC NMR in a single mixture of all linear aldohexoses. Data were fitted to (a) a first order or (b) a second order reaction model. Reaction conditions: $10 \mathrm{mg}$ of each aldohexose, $15 \mathrm{mg} \mathrm{SnCl} \cdot 5 \mathrm{H}_{2} \mathrm{O}$, $100{ }^{\circ} \mathrm{C}$ and $0.6 \mathrm{ml} \mathrm{DMSO}-\mathrm{d}_{6}$.

\subsection{Hexose conversion with $\mathrm{HCl}$ is bi-exponential}

Mechanistic differences between Lewis acid and Brønsted acid catalyzed carbohydrate conversions are expectable and should be reflected by dissimilar conversion kinetics. For comparison with the reactions catalyzed by Lewis acidic salts, the reaction progress of glucose conversion to HMF was followed for the Brønsted acid catalyzed conversion $\left(40 \mathrm{mM} \mathrm{HCl}\right.$ in DMSO at $\left.130^{\circ} \mathrm{C}\right)$. Neither glucose conversion nor the formation of HMF were indicative of second order kinetics (Fig. 4). In the Brønsted acid catalyzed conversion of glucose to HMF, $\beta$-anhydroglucose (first in its furanose and subsequently in its pyranose form) [27] accumulated in competition to slower glucose conversion to HMF (Fig. S13). The rate constants of the two kinetic regimes of glucose conversion differ by more than twentyfold. The efficient conversion of glucose to HMF in Brønsted acidic aprotic media thus depends on the extent of competing anhydroglucose formation and the possibility of its avoidance. This finding is consistent with previous observations that addition of water can be beneficial for HMF formation from glucose in aprotic solvent [31]. Analogously, intramolecular ketalization occurs when fructose is the substrate. Also for fructose, conversion in aprotic Brønsted acidic medium thus shows biexponential rather than exponential kinetics (Fig. S14). This behavior is somewhat reminiscent of the ketalization of fructose to methyl fructosides in competition with the conversion to the thermodynamic product methyl lactate for the Sn-Beta catalyzed carbohydrate conversion in methanol [26]. 


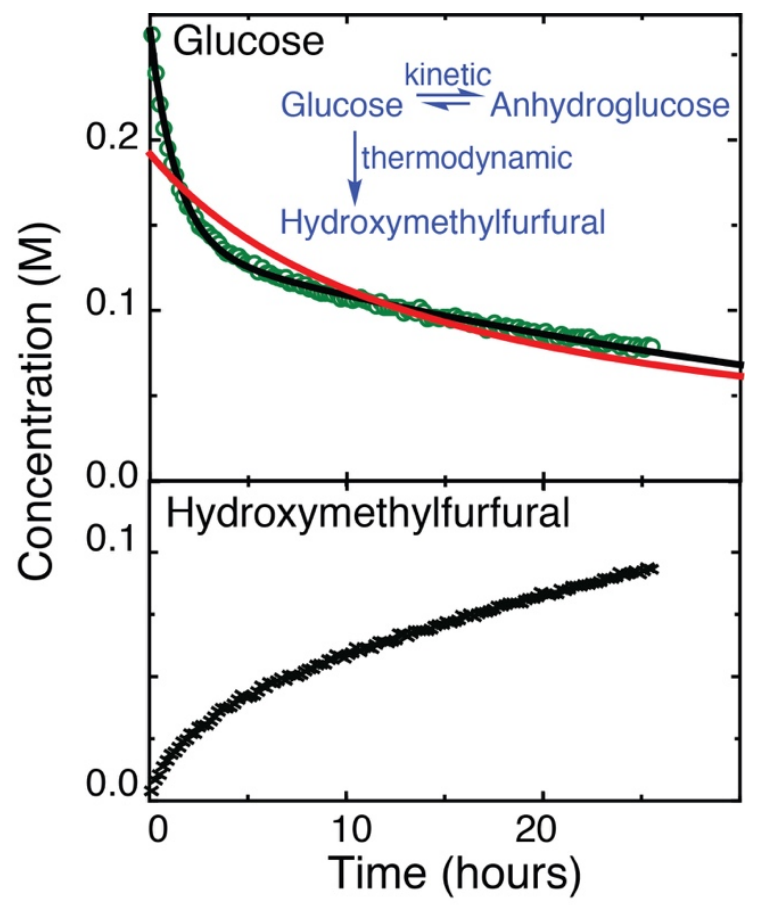

Figure 4. Brønsted acid catalyzed conversion of glucose in DMSO to anhydroglucose and HMF as tracked by a series of 1D ${ }^{13} \mathrm{C}$ NMR spectra. Concentrations can be described by bi-exponential kinetics due to competing formation of kinetic and thermodynamic product (see inset). Reaction conditions: $25 \mathrm{mg}\left[1-{ }^{13} \mathrm{C}\right]$ glucose, $40 \mathrm{mM} \mathrm{HCl}, 130{ }^{\circ} \mathrm{C}, 0.6 \mathrm{ml} \mathrm{DMSO}-$ $\mathrm{d}_{6}$.

\section{Conclusions}

Real time in situ NMR spectroscopy was used to track monosaccharide conversion by Lewis and Brønsted acidic catalysts in polar aprotic solvents. Slow conversion regimes posed a notable challenge to the full conversion especially of aldoses. Aldoses displayed second order reaction kinetics that were very little affected by compounds implicated in intermolecular aggregation. Ketoses exhibited reaction kinetics that were consistent with first order reactions along the entire reaction path. Limitations in reaching high conversion of glucose as a consequence of the reaction mechanism were equally inherent to Brønsted acid catalyzed conversion of Glucose to HMF. Here, competing reactions to masked anhydrosugars resulted in bi-exponential kinetics, where the rate constants of the two kinetic regimes differed by more than twentyfold for glucose conversion and by approximately tenfold for fructose conversion.

\section{Acknowledgements}


This work was funded by the Innovation Fund Denmark (case number 5150-00023B). NMR spectra were recorded on the spectrometers of the DTU NMR center supported by the Carlsberg and the Villum foundations.

\section{References}

[1] S. Hu, Z. Zhang, J. Song, Y. Zhou, B. Han, Efficient conversion of glucose into 5-hydroxymethylfurfural catalyzed by a common Lewis acid SnCl4 in an ionic liquid, Green Chem., 11 (2009) pp. 1746-1749.

[2] M. Watanabe, Y. Aizawa, T. lida, T.M. Aida, C. Levy, K. Sue, H. Inomata, Glucose reactions with acid and base catalysts in hot compressed water at 473K, Carbohydr. Res., 340 (2005), pp. 1925-1930.

[3] A. Corma, S. Iborra, A. Velty, Chemical Routes for the Transformation of Biomass into Chemicals, Chem. Rev., 107 (2007), pp. 2411-2502.

[4] G.R. Akien, L. Qi, I.T. Horvath, Molecular mapping of the acid catalysed dehydration of fructose, Chem. Commun., 48 (2012), pp. 5850-5852.

[5] V. Choudhary, S.H. Mushrif, C. Ho, A. Anderko, V. Nikolakis, N.S. Marinkovic, A.I. Frenkel, S.I. Sandler, D.G. Vlachos, Insights into the Interplay of Lewis and Brønsted Acid Catalysts in Glucose and Fructose Conversion to 5-(Hydroxymethyl)furfural and Levulinic Acid in Aqueous Media, J. Am. Chem. Soc., 135 (2013), pp. 3997-4006.

[6] B.F.M. Kuster, 5-Hydroxymethylfurfural (HMF). A Review Focussing on its Manufacture, Starch - Stärke, 42 (1990), pp. $314-321$.

[7] R.-J. van Putten, J.C. van der Waal, E. de Jong, C.B. Rasrendra, H.J. Heeres, J.G. de Vries, Hydroxymethylfurfural, A Versatile Platform Chemical Made from Renewable Resources, Chem. Rev., 113 (2013), pp. 1499-1597.

[8] B. Saha, M.M. Abu-Omar, Advances in 5-hydroxymethylfurfural production from biomass in biphasic solvents, Green Chem., 16 (2014), pp. 24-38.

[9] H. Zhao, J.E. Holladay, H. Brown, Z.C. Zhang, Metal chlorides in ionic liquid solvents convert sugars to 5-hydroxymethylfurfural, Science, 316 (2007), pp. 1597-1600.

[10] A.S. Amarasekara, L.D. Williams, C.C. Ebede, Mechanism of the dehydration of D-fructose to 5-hydroxymethylfurfural in dimethyl sulfoxide at 150 degrees C: an NMR study, Carbohydr. Res., 343 (2008), pp. 3021-3024.

[11] J. Zhang, E. Weitz, An in Situ NMR Study of the Mechanism for the Catalytic Conversion of Fructose to 5-Hydroxymethylfurfural and then to Levulinic Acid Using 13C Labeled d-Fructose, ACS Catalysis, 2 (2012), pp. 1211-1218.

[12] S. Saravanamurugan, A. Riisager, E. Taarning, S. Meier, Mechanism and stereoselectivity of zeolite-catalysed sugar isomerisation in alcohols, Chem. Commun., 52 (2016), pp. 12773-12776.

[13] S. Saravanamurugan, A. Riisager, E. Taarning, S. Meier, Combined Function of Brønsted and Lewis Acidity in the Zeolite-Catalyzed Isomerization of Glucose to Fructose in Alcohols, ChemCatChem, 8 (2016), pp. 3107-3111.

[14] S.G. Elliot, S. Tolborg, I. Sadaba, E. Taarning, S. Meier, Quantitative NMR Approach to Optimize the Formation of Chemical Building Blocks from Abundant Carbohydrates, ChemSusChem, 10 (2017), pp. 2990-2996.

[15] S.G. Elliot, E. Taarning, R. Madsen, S. Meier, NMR Spectroscopic Isotope Tracking Reveals Cascade Steps in Carbohydrate Conversion by Tin-Beta, ChemCatChem, 10 (2018), pp. 1414-1419.

[16] H.-S. Chen, A. Wang, H. Sorek, J.D. Lewis, Y. Román-Leshkov, A.T. Bell, Production of Hydroxyl-rich Acids from Xylose and Glucose Using Sn-BEA Zeolite, ChemistrySelect, 1 (2016), pp. 4167-4172.

[17] S. Tolborg, S. Meier, I. Sádaba, S.G. Elliot, S.K. Kristensen, S. Saravanamurugan, A. Riisager, P. Fristrup, T. Skrydstrup, E. Taarning, Tin-containing silicates: Identification of a glycolytic pathway via 3-deoxyglucosone, Green Chem., 18 (2016), pp. 3360-3369. 
[18] R. Bermejo-Deval, M. Orazov, R. Gounder, S.-J. Hwang, M.E. Davis, Active Sites in Sn-Beta for Glucose Isomerization to Fructose and Epimerization to Mannose, ACS Catalysis, 4 (2014), pp. 2288-2297.

[19] A.V. Yakimov, Y.G. Kolyagin, S. Tolborg, P.N.R. Vennestrøm, I.I. Ivanova, 119Sn MAS NMR Study of the Interaction of Probe Molecules with Sn-BEA: The Origin of Penta- and Hexacoordinated Tin Formation, J. Phys. Chem. C, 120 (2016), pp. 28083-28092.

[20] C.B. Rasrendra, J.N.M. Soetedjo, I.G.B.N. Makertihartha, S. Adisasmito, H.J. Heeres, The Catalytic Conversion of d-Glucose to 5Hydroxymethylfurfural in DMSO Using Metal Salts, Topics in Catalysis, 55 (2012), pp. 543-549.

[21] X. Qi, M. Watanabe, T.M. Aida, R.L. Smith Jr, Fast Transformation of Glucose and Di-/Polysaccharides into 5Hydroxymethylfurfural by Microwave Heating in an Ionic Liquid/Catalyst System, ChemSusChem, 3 (2010), pp. 1071-1077.

[22] X. Qi, M. Watanabe, T.M. Aida, J.R.L. Smith, Efficient process for conversion of fructose to 5-hydroxymethylfurfural with ionic liquids, Green Chemistry, 11 (2009), pp. 1327-1331.

[23] M.J. Antal Jr, T. Leesomboon, W.S. Mok, G.N. Richards, Mechanism of formation of 2-furaldehyde from d-xylose, Carbohydr. Res., 217 (1991), pp. 71-85.

[24] T. Wang, M.W. Nolte, B.H. Shanks, Catalytic dehydration of C6 carbohydrates for the production of hydroxymethylfurfural (HMF) as a versatile platform chemical, , Green Chem., 16 (2014), pp. 548-572.

[25] X. Qian, M.R. Nimlos, M. Davis, D.K. Johnson, M.E. Himmel, Ab initio molecular dynamics simulations of $\beta$-d-glucose and $\beta$-dxylose degradation mechanisms in acidic aqueous solution, Carbohydr. Res., 340 (2005), pp. 2319-2327.

[26] I. Tosi, A. Riisager, E. Taarning, P.R. Jensen, S. Meier, Kinetic analysis of hexose conversion to methyl lactate by Sn-Beta: effects of substrate masking and of water, Cat. Sci. Technol., 8 (2018), pp. 2137-2145.

[27] I. Tosi, S.G. Elliot, B.M. Jessen, A. Riisager, E. Taarning, S. Meier, Uncharted Pathways for CrCl3 Catalyzed Glucose Conversion in Aqueous Solution, Topics in Catalysis, 62, (2019), pp. 669-677.

[28] K. Dussan, B. Girisuta, M. Lopes, J.J. Leahy, M.H.B. Hayes, Conversion of Hemicellulose Sugars Catalyzed by Formic Acid: Kinetics of the Dehydration of D-Xylose, L-Arabinose, and D-Glucose, ChemSusChem, 8 (2015), pp. 1411-1428.

[29] V. Tarabanko, M. Smirnova, M. Chernyak, A. Kondrasenko, N. Tarabanko, The Nature and Mechanism of Selectivity Decrease of the Acid-catalyzed Fructose Conversion with Increasing the Carbohydrate Concentration, J. Sib. Fed. Univ. Chem., 1 (2015), pp. 6-18. [30] W. Deng, P. Wang, B. Wang, Y. Wang, L. Yan, Y. Li, Q. Zhang, Z. Cao, Y. Wang, Transformation of cellulose and related carbohydrates into lactic acid with bifunctional Al(iii)-Sn(ii) catalysts, Green Chem., 20 (2018), pp. 735-744.

[31] S. Jia, Z. Xu, Z.C. Zhang, Catalytic conversion of glucose in dimethylsulfoxide/water binary mix with chromium trichloride: Role of water on the product distribution, Chem. Eng. J., 254 (2014) 333-339.

[32] P.R. Jensen, E. Taarning, S. Meier, Probing the Lewis Acid Catalyzed Acyclic Pathway of Carbohydrate Conversion in Methanol by In Situ NMR, ChemCatChem, 11 (2019) 5077-5084.

[33] H. Nguyen, V. Nikolakis, D.G. Vlachos, Mechanistic Insights into Lewis Acid Metal Salt-Catalyzed Glucose Chemistry in Aqueous Solution, ACS Catal., 6 (2016), pp. 1497-1504.

[34] E. Taarning, I. Sádaba, P.R. Jensen, S. Meier, Discovery and Exploration of the Efficient Acyclic Dehydration of Hexoses in DMSO/Water, ChemSusChem, (2019), https://doi.org/10.1002/cssc.201902322. 